\title{
The Anticancer Activity of the Old Neuroleptic Phenothiazine-type Drug Thioridazine
}

\author{
GABRIELLA SPENGLER ${ }^{1}$, ÁKOS CSONKA ${ }^{1}$, JOSEPH MOLNÁR $^{1}$ and LEONARD AMARAL ${ }^{1,2}$ \\ ${ }^{1}$ Department of Medical Microbiology and Immunobiology, \\ Faculty of Medicine, University of Szeged, Szeged, Hungary; \\ ${ }^{2}$ Travel Medicine, Instituto de Higiene e Medicina Tropical, \\ Universidade Nova de Lisboa, Lisbon, Portugal
}

\begin{abstract}
Thioridazine (TZ), an antipsychotic drug, renders multidrug-resistant (MDR) cancer cells susceptible to cytotoxic agents to which they were initially resistant, has antiprolilferative activity and apoptosis-inducing properties in various tumor cell lines and cancer stem cells. Whereas the anti-proliferative activity takes place at high concentrations that ensure the intercalation of the compound between nucleic bases (especially rich in $G / C$ bases), much lower concentrations inhibit the export function of the ABCBI (P-glycoprotein), which is responsible for the MDR phenotype of the cancer cell. The co-administration of $T Z$ with doxorubicin inhibits efflux of doxorubicin and, hence, increases the intracellular concentration of anticancer drug. The (+) and (-) enantiomers of TZ have the same activities as TZ. The main focus of this review is to present extensive evidence provided by our work, confirmed by much later studies, as it supports adjuvant use of $T Z$ with an anticancer drug for MDR cancer therapy.
\end{abstract}

Phenothiazines are heterocyclic compounds that have specific and non-specific activities against constituents of the plasma membrane of eukaryotes. Although the first phenothiazines were synthesized in the late 19th century, the basic phenothiazine structure is identical to that of the well-

This article is freely accessible online

Correspondence to: Gabriella Spengler, Department of Medical Microbiology and Immunobiology, Faculty of Medicine, University of Szeged, Dóm tér 10, H-6720 Szeged, Hungary. Tel: +36 62545115, Fax: +36 62545113, e-mail: spengler.gabriella@med.uszeged.hu

Key Words: Phenothiazines, thioridazine, thioridazine derivatives, multidrug-resistant cancer cell lines, resistance to doxorubicin, inhibition of P-glycoprotein (ABCB1), reversal of multidrug resistance, inhibition of replication, induction of apoptosis, review. known dye methylene blue, which was first prepared as a stain in 1876 by the German chemist Heinrich Caro as a derivative from an existing phenothiazine (1). Paul Ehrlich studied methylene blue (Figure 1) for biological properties and found that it could reduce the mobility of bacteria (1). The demonstration by Bodoni at the end of the 19th century that methylene blue could render a human lethargic, spurred investigations of the possible use of this dye to control psychosis (2). It took more than 50 years to produce a colorless methylene blue-type compound by the French chemist Charpentier of Rhone-Poulenc called chlorpromazine (CPZ) that had the desired neuroleptic properties for therapy psychosis (3). However, because of its toxic side-effects, the compound was soon replaced with the equally effective phenothiazine neuroleptic thioridazine (TZ) whose most frequent side-effect was somnolence (Figure 1). The early wide use of CPZ indicated that, apart from their basic neuroleptic action related to the blockade of dopaminergic receptors, CPZ affected diverse biological activities, such as the calcium transporter calmodulin, protein kinase $\mathrm{C}$, as well as many other enzymes that, when inhibited by CPZ, promoted anti-proliferative effects $(4,5)$. The enhancement of antibiotic activity by $\mathrm{CPZ}$ on bacteria and the demonstration that multidrug-resistant (MDR) Mycobacterium tuberculosis could be inhibited in its replication by $\mathrm{CPZ}$ and $\mathrm{TZ}$ (6) as well as the reversal of antibiotic resistance was the result of inhibition of the efflux pump system of mycobacteria (6) and bacteria (7). In addition, similar inhibitory effects of the ABCB1 transport function were demonstrated using MDR mouse T-lymphoma cells (8). The relevant possibilities to MDR cancer were supported by the anti-helmintic and antibacterial activities of phenothiazines described in the 1930s and 1940s (5). Phenothiazines have been in use for the treatment of psychiatric disorders since the 1950s. In addition, various other effects of phenothiazines have since been described, 
<smiles>CN(C)c1ccc2nc3ccc(=[N+](C)C)cc-3sc2c1</smiles>

Methylene blue<smiles>CSc1ccc2c(c1)N(CC[C@H]1CCCCN1C)c1ccccc1S2</smiles>

Figure 1. Chemical structure of some important phenothiazines.<smiles>CN(C)CCCN1c2ccccc2Sc2ccc(Cl)cc21</smiles>

Chlorpromazine<smiles>CSc1ccc2c(c1)N(CC[C@H]1CCCCN1C)c1ccccc1S2</smiles>

such as anti-mycobacterial (9), anti-plasmid (10) and immunomodulatory (11) activities. The substituents in the phenothiazine ring, which increase lipophilicity, amplify their anti-proliferative activity in cancer cells (12). The presence of different substituents into the phenothiazine skeleton, as well as the modification of the tricyclic ring system, alters their biological effect (13). Because of their highlighted biological activity, numerous derivatives of phenothiazines have been synthesized and patented (5).

Thioridazine, (10-[2-(1-methyl-2-piperidinyl)ethyl]-2(methylthio)-10H-phenothiazine), was previously used extensively as an antipsychotic drug; however, there is an increasing number of studies demonstrating its anticancer, multidrug resistance-reversing and apoptosis-inducing properties in various tumor cell lines. This review intends to give an overview of the MDR-reversing activity of thioridazine that has resulted from our decades of published research studies, many of which have been recently confirmed by others, although correct citation of their existence has been omitted willfully or otherwise.

\section{Membrane Destabilizing Effects}

Phenothiazines demonstrate a strong affinity to lipid bilayers of cell membranes because of the high degree of lipophilicity of the phenothiazine ring (12). Thioridazine (TZ) interacts with the inner mitochondrial membrane. Consequently, TZ presents with antioxidant and peroxidation activities on membrane lipids of the mitochondria, with these effects resulting in transient alterations of mitochondrial permeability, thus promoting release of cytochrome $c$ from mitochondria (14).

\section{Effect on Cell Cycle}

According to in silico gene signature based studies, TZ inhibits the phosphatidylinositol-3'-kinase (PI3K)/Akt pathway and, thus, exerts cytotoxicity in ovarian cancer cells (15).

Translationally controlled tumor protein (TCTP) is an essential regulator of apoptosis and cell cycle events (16). In 508 breast cancers, high-TCTP status is associated with aggressive G3-grade tumors, predicting poor prognosis. TZ increases P53 expression by counteracting the ubiquitination of P53 that is enhanced by TCTP (17).

\section{Anti-calmodulin Activity}

Calmodulin is a calcium binding protein that regulates calcium-dependent biochemical processes and, hence is involved in a large variety of cellular functions. Since TZ is a potent inhibitor of calmodulin, calcium binding and many calcium-dependent enzymes that are involved in cellular proliferation become destabilized. Thus, when calmodulin is 
inhibited from binding calcium by TZ, these enzymes deny access to calcium, and, hence, their reduced activity results in the inhibition of cell proliferation (12). Similarly, many biochemical pathways, dependent upon access to calcium, are similarly inhibited $(12,18)$.

\section{Effect on DNA Damage}

TZ can interfere with DNA damage responses and DNA repair. Furthermore, TZ is an inhibitor of Tousled-like kinases (TLKs), enzymes responsible for the maintenance of genomic stability (19). As described previously, TZ has antiplasmid activity by eliminating the drug resistance-carrying plasmids of bacteria (20).

\section{TZ as Dopamine Receptor Antagonist}

$\mathrm{TZ}$ is an antagonist of the dopamine D2 receptor (DRD2) and, according to previous reports, DRD2 could be a promising therapeutic target in cervical cancer therapy. It has been shown that $\mathrm{TZ}$ inhibits cellular proliferation through down-regulation of DRD2 expression. Moreover, TZ can inhibit proliferation of human uterine cervical carcinoma cells and induce apoptosis and necrosis (21). TZ can inhibit the PI3K/Akt/mTOR/p70S6K signaling pathway and has cytotoxic activity on cervical and endometrial cancer cells by inducing cell cycle arrest and apoptosis (22).

\section{Activity on Stem Cells}

$\mathrm{TZ}$ is a selective inducer of the differentiation of cancer stem cells (CSC) and the anti-CSC activity of TZ is due to its antagonistic effect on DRD2 receptors that are differentially expressed on neoplastic stem cells. It is important to note that $\mathrm{TZ}$ has no effect on normal human somatic stem cells implying that $\mathrm{TZ}$ could be a selective anti-CSC drug (23).

TZ exerts an apoptotic effect in brain-derived tumors; furthermore, the sensitivity of neoplasm tissue to thioridazine is higher than that on primary (normal) brain cells (24). With the use of bioinformatic tools, it has been demonstrated that $\mathrm{TZ}$ is a potent anti-glioblastoma and anti-glioblastoma cancer stem-like cell agent. Moreover, because autophagy might be a major mechanism of the anti-glioblastoma activity and TZ has proved to be an effective glioblastoma tumor growth inhibitor that can induce autophagy in vivo, the rediscovery of $\mathrm{TZ}$ as an anticancer agent could be used as a powerful strategy against malignant tumors with a poor prognosis (25).

\section{Apoptosis Induction}

$\mathrm{TZ}$ induces apoptosis in leukemic cells without any influence on the viability of normal lymphocytes (26). It also induces apoptosis of B16 melanoma cells and demonstrates in vivo anti-tumor activity (27). The in vivo activity of $\mathrm{TZ}$ was studied using female C57/B1 mice. Animals were inoculated with wild-type B16 melanoma cells by intravenous (i.v.) injection into the tail vein. Mice were treated with TZ (10 and $15 \mathrm{mg} / \mathrm{kg} \times 3 /$ weeks intraperitoneally (i.p.) or 15 and 25 $\mathrm{mg} / \mathrm{kg} /$ day per os (p.o.)) and, after autopsy, the lung weight and number of pulmonary melanoma colonies were determined. $\mathrm{TZ}$ administration (i.p. or p.o.) resulted in the reduction of lung tumor burden and an increase in mice survival (27).

It was demonstrated that $\mathrm{TZ}$ induces apoptosis of the MDR mouse T-lymphoma cells at 5 and $10 \mu \mathrm{g} / \mathrm{ml}$ concentrations (8). During apoptosis, the plasma membrane undergoes multiple changes: the translocation of phosphatidylserine from the inner to the outer leaflet of the plasma membrane can be detected by annexin V. After treatment with $10 \mu \mathrm{g} / \mathrm{ml}$ of $\mathrm{TZ}, 49.54 \%$ of the cells were early-apoptotic and $27.26 \%$ showed late-apoptotic and necrotic features, although the proportion of dead cells was $3.4 \%$ in MDR mouse T-lymphoma cells (8). The apoptosisinducing effect of $\mathrm{TZ}$ was confirmed by other studies using various cell lines (28).

\section{Efflux Pump Inhibition}

The major mechanism for the MDR phenotype is the overexpression of ATP-dependent transporters known as the ATP-binding cassette (ABC) family. In humans, the three major types of MDR proteins include members of the $A B C B$ (ABCB1/MDR1/P-glycoprotein), the ABCC (ABCC1/MRP1, ABCC2/MRP2, probably also ABCC3-6 and ABCC10-11) and the ABCG (ABCG2/MXR/BCRP) sub-family (29). The relationship between $\mathrm{ABC}$ expression levels and sensitivity to drugs or possible drug candidates is of great importance concerning anticancer chemotherapy.

Substances, such as verapamil and TZ, which can block ABCB1 or P-glycoprotein, can reverse resistance of doxorubicin-resistant sarcoma 180 (S180) cells completely (30). According to Spengler et al., TZ induces apoptosis of the MDR lymphoma cells and inhibits the activity of their overexpressed ABCB1 transporter. However, the concentrations that produce these in vitro results are extremely high and greater than that clinically employed for the therapy of severe psychosis (8).

\section{Anti-angiogenesis}

Angiogenesis is essential for tumor growth and metastasis and targeting angiogenesis could be a promising objective for anticancer drug development. Expression of vascular endothelial growth factor (VEGF) and hypoxia-inducible factor $1 \alpha(\mathrm{HIF}-1 \alpha)$, as well as the phosphorylation of VEGFR-2 were reduced in a thioridazine-treated tumor (31). 
$\mathrm{TZ}$ is an angiostatic agent found to effectively inhibit angiogenesis in a murine tumor model reducing microvessel density in vivo (32).

\section{Stereochemistry and Pharmacological Activity}

The consideration of stereochemistry in drug action is gaining ever-greater attention in medical practice. Many of the drugs currently used in psychiatric practice are mixtures of enantiomers. For some therapeutics, single-enantiomer formulations can provide greater selectivity for their biological targets and/or better pharmacokinetics compared to the mixture of enantiomers. When both a single enantiomer and a racemic formulation of a drug are available, the information from experimental evidences should be used to decide which formulation is most appropriate (33). The potential advantages of using single enantiomers of a chiral drug were investigated by Csonka et al. (34). The equilibrium between the (+) and $(-)$ isomers influences the binding affinities of the enantiomers to different ligands or receptors. "Do the racemate $\mathrm{TZ}$ and its enantiomers express different activities against cancer cell lines?" This question was based upon observations published by others who suggested that "the (-)-TZ enantiomer had slightly more catalepsy (neuroleptic)" (35). Nevertheless, a variety of pharmacological studies, as reported by Svendsen et al. (35), indicate significantly greater binding of the (-)-TZ enantiomer to the D1 receptor of the rodent brain. Regardless, our results clearly demonstrate that the racemate $\mathrm{TZ}$ and its enantiomers have essentially the same activity against cancer cell lines with respect to the inhibition of replication, induction of apoptosis and inhibition of ABCB1 (34). The central nervous system (CNS) receptor stereospecificity of $(+)$ and (-)-TZ was first described by Svendsen et al. in 1988 (35). Optical isomers, such as those of TZ, exhibit significant differences in their affinities for receptor sites, biotransformation and binding to serum and tissue proteins. Separation of the racemate $\mathrm{TZ}$ into its enantiomers in the human body has been measured (36). In these investigations, the (-) enantiomer was found to be at higher concentrations than the $(+)$ enantiomer in the different tissues. The general possibility for using the resolution of commercially available racemates in therapeutics for an anxiolytic effect has been described by Baumann et al. (36) based on the investigations and statements made by Ariens et al. (37). The role of the chirality of other compounds known to affect ABCB1, such as the enantiomers of verapamil, has been investigated. These latter studies indicated that the $\mathrm{L}$ and the $\mathrm{D}$ forms of verapamil had equal abilities to reverse the in vitro resistance of MDR leukemic cells to drugs, such as vincristine (38). The mechanism of action of TZ has been analyzed in detail by Spengler et al. who showed that the racemate is able to induce the apoptosis of MDR mouse T-lymphoma cells (8). In this latter study, the differential effects of the two TZ enantiomers were not examined. As previously stated, the anti-proliferative effects of the racemate and (+) and (-) enantiomers of $\mathrm{TZ}$ on MDR mouse T-lymphoma cells overexpressing ABCB1 were investigated by Csonka et al. (34) and no significant differences were found between the three compounds.

In order to avoid the toxic side-effect of resistance-reversing compounds, drugs with selective inhibition of the MDR in cancer cells are needed. To achieve this effect, three classes of known neuroleptic drugs (methotrimeprazine, clopenthixol and butaclamol isomers) with active and inactive stereoisomers were tested for MDR efflux pump inhibition on mouse Tlymphoma cell lines (39). Their anti-proliferative effects on sensitive and MDR cancer cell cultures were compared with those of the classical resistance modifier verapamil. It was confirmed that enantiomers of phenylalkylamines proved to be equally potent inhibitors of drug transport by ABCB1 (39). However, CNS-active and -inactive butaclamol enantiomers exerted slightly different effects on the reversal of the MDR phenotype, which means that drug binding might have weak enantioselectivity for ABCB1 (39), suggesting that some enantiomers of compounds that inhibit ABCB1 can be exploited as adjuvants to cytostatic chemotherapy of cancer in order to increase the efficacy of the anticancer agent. However, the separate use of one enantiomer of $\mathrm{TZ}$ versus the other did not appear to provide any advantage over racemic $\mathrm{TZ}$ for the adjuvant therapy of MDR cancer.

\section{Role of TZ in Combined Chemotherapy}

The combination therapy using a conventional chemotherapeutic drug with an agent that can improve the action of the anticancer drug without any additional sideeffects could be a good approach to treat MDR cancer. TZ showed a moderate synergism to doxorubicin in P388/ADR murine leukemia cells described by Ramu et al. (40).

It has been confirmed that calmodulin inhibitors significantly enhanced the cytotoxic effects of doxorubicin in the resistant but not parent-sensitive P388 cells (41). To administer $\mathrm{TZ}$ and doxorubicin to in vitro and in vivo systems, polymeric micelles have been designed as delivery carriers (42). The combination therapy with TZ-free or TZloaded micelles was effective in decreasing the population of cancer stem cells. However, TZ-loaded micelles had lower antitumor efficacy than doxorubicin-loaded micelles; the combination therapy of TZ-loaded and doxorubicin-loaded micelles presented a greater antitumor effect than doxorubicin-loaded micelles alone (42).

\section{Conclusion}

The first demonstrations that phenothiazines could inhibit cancer growth were reported during the early 1950s. Since those early years, many studies have been published 
describing that phenothiazines can inhibit the growth of some types of cancers (43). Based on the biological activity of TZ, such as interference with membrane function, DNA repair, signaling pathways, cell cycle, apoptosis induction, efflux inhibition and, also, its synergistic effect with doxorubicin, renders TZ a powerful anticancer drug and adjuvant in combined chemotherapy.

\section{Acknowledgements}

This research was supported by the Szeged Foundation for Cancer Research, the European Union and the State of Hungary, cofinanced by the European Social Fund in the framework of TÁMOP 4.2.4. A/2-11-1-2012-0001 'National Excellence Program'. This paper was supported by the János Bolyai Research Scholarship of the Hungarian Academy of Sciences.

\section{References}

1 Oz M, Lorke De, Hasan M and Petroianu GA: Cellular and molecular actions of Methylene Blue in the nervous system. Med Res Rev 31(1): 93-117, 2011.

2 Bodoni P: Dell'azione sedativa del bleu di metilene in varie forme di psicosi. Clin Med Ital 24: 217-222, 1899.

3 Charpentier P, Gaillot P, Jacob R, Gaudechon J and Buisson P: Recherches sur les dimethylaminopropyl $N$-phenothiazines. C. R. Aux Acad Sci 235: 59-60, 1952.

4 Curzon G: How reserpine and chlorpromazine act: The impact of key discoveries on the history of psychopharmacology. Trends Pharmacol Sci 11(2): 61-63, 1990.

5 Ohlow MJ and Moosmann B: Phenothiazine: The seven lives of pharmacology's first lead structure. Drug Discov Today 16(3-4): 119-131, 2011.

6 Amaral L, Kristiansen JE, Abebe LS and Millett W: Inhibition of the respiration of multi-drug resistant clinical isolates of Mycobacterium tuberculosis by thioridazine: Potential use for initial therapy of freshly diagnosed tuberculosis. J Antimicrob Chemother 38(6): 1049-1053, 1996.

7 Spengler G, Rodrigues L, Martins A, Martins M, McCusker M, Cerca P, Machado L, Costa SS, Ntokou E, Couto I, Viveiros M, Fanning S, Molnar $\mathrm{J}$ and Amaral L: Genetic response of Salmonella enterica serotype Enteritidis to thioridazine rendering the organism resistant to the agent. Int $\mathbf{J}$ Antimicrob Agents 39(1): 16-21, 2012.

8 Spengler G, Molnar J, Viveiros M and Amaral L: Thioridazine induces apoptosis of multidrug-resistant mouse lymphoma cells transfected with the human ABCB1 and inhibits the expression of P-glycoprotein. Anticancer Res 31(12): 4201-4205, 2011.

9 Martins M, Schelz Z, Martins A, Molnar J, Hajos G, Riedl Z, Viveiros M, Yalcin I, Aki-Sener E and Amaral L: In vitro and $e x$ vivo activity of thioridazine derivatives against Mycobacterium tuberculosis. Int J Antimicrob Agents 29(3): 338-340, 2007.

10 Motohashi N, Sakagami H, Kurihara T, Csuri K and Molnar J: Antiplasmid activity of phenothiazines, benzo[a]phenothiazines and benz[c]acridines. Anticancer Res 12(1): 135-139, 1992.

11 Molnar J, Mandi Y, Petri I, Petofi S, Sakagami H, Kurihara T and Motohashi N: Immunomodulation activity of phenothiazines, benzo[a]phenothiazines and benz[c]acridines. Anticancer Res 13(2): 439-442, 1993.
12 Jaszczyszyn A, Gąsiorowski K, Świątek P, Malinka W, CieślikBoczula K, Petrus J and Czarnik-Matusewicz B: Chemical structure of phenothiazines and their biological activity. Pharmacol Rep 64(1): 16-23, 2012.

13 Pluta K, Morak-Młodawska B and Jeleń M: Recent progress in biological activities of synthesized phenothiazines. Eur J Med Chem 46(8): 3179-3189, 2011.

14 Rodrigues T, Santos AC, Pigoso AA, Mingatto FE, Uyemura SA and Curti C: Thioridazine interacts with the membrane of mitochondria acquiring antioxidant activity toward apoptosis potentially implicated mechanisms. Br J Pharmacol 136(1): 136$142,2002$.

15 Rho SB, Kim BR and Kang S: A gene signature-based approach identifies thioridazine as an inhibitor of phosphatidylinositol-3'kinase $(\mathrm{PI} 3 \mathrm{~K}) / \mathrm{AKT}$ pathway in ovarian cancer cells. Gynecol Oncol 120(1): 121-127, 2011.

16 Tuynder M, Fiucci G, Prieur S, Lespagnol A, Géant A, Beaucourt S, Duflaut D, Besse S, Susini L, Cavarelli J, Moras $\mathrm{D}$, Amson R and Telerman A: Translationally controlled tumor protein is a target of tumor reversion. Proc Natl Acad Sci USA 101(43): 15364-15369, 2004.

17 Amson R, Pece S, Lespagnol A, Vyas R, Mazzarol G, Tosoni D, Colaluca I, Viale G, Rodrigues-Ferreira S, Wynendaele J, Chaloin O, Hoebeke J, Marine JC, Di Fiore PP and Telerman A: Reciprocal repression between P53 and TCTP. Nat Med 18(1): 91-99, 2011.

18 Pantazaki AA, Lialiaris TS: A combined biochemical and cytogenetic study of thioridazine-induced damage to nucleic acids. Mutagenesis 14(2): 243-8, 1999.

19 Ronald S, Awate S, Rath A, Carroll J, Galiano F, Dwyer D, Kleiner-Hancock H, Mathis JM, Vigod S and De Benedetti A: Phenothiazine inhibitors of TLKs affect double-strand break repair and DNA damage response recovery and potentiate tumor killing with radiomimetic therapy. Genes Cancer 4(1-2): 39-53, 2013.

20 Molnár J: Antiplasmid activity of tricyclic compounds. Methods Find Exp Clin Pharmacol 10(7): 467-474, 1988.

21 Mao M, Yu T, Hu J and Hu L: Dopamine D2 receptor blocker thioridazine induces cell death in human uterine cervical carcinoma cell line SiHa. J Obstet Gynaecol Res 41(8): 12401245,2015

22 Kang S, Dong SM, Kim BR, Park MS, Trink B, Byun HJ and Rho SB: Thioridazine induces apoptosis by targeting the $\mathrm{PI} 3 \mathrm{~K} / \mathrm{Akt} / \mathrm{mTOR}$ pathway in cervical and endometrial cancer cells. Apoptosis 17(9): 989-997, 2012.

23 Sachlos E, Risueño RM, Laronde S, Shapovalova Z, Lee JH, Russell J, Malig M, McNicol JD, Fiebig-Comyn A, Graham M, Levadoux-Martin M, Lee JB, Giacomelli AO, Hassell JA, Fischer-Russell D, Trus MR, Foley R, Leber B, Xenocostas A, Brown ED, Collins TJ and Bhatia M: Identification of drugs including a dopamine receptor antagonist that selectively target cancer stem cells. Cell 149(6): 1284-1297, 2012.

24 Gil-Ad I, Shtaif B, Levkovitz Y, Dayag M, Zeldich E and Weizman A: Characterization of phenothiazine-induced apoptosis in neuroblastoma and glioma cell lines: Clinical relevance and possible application for brain-derived tumors. $\mathbf{J}$ Mol Neurosci 22(3): 189-198, 2004.

25 Cheng HW, Liang YH, Kuo YL, Chuu CP, Lin CY, Lee MH, Wu AT, Yeh CT, Chen EI, Whang-Peng J, Su CL and Huang CY: Identification of thioridazine, an antipsychotic drug, as an antiglioblastoma and anticancer stem cell agent using public gene expression data. Cell Death Dis 6: e1753, 2015. 
26 Zhelev Z, Ohba H, Bakalova R, Hadjimitova V, Ishikawa M, Shinohara $\mathrm{Y}$ and Baba Y: Phenothiazines suppress proliferation and induce apoptosis in cultured leukemic cells without any influence on the viability of normal lymphocytes. Phenothiazines and leukemia. Cancer Chemother Pharmacol 53(3): 267-275, 2004.

27 Gil-Ad I, Shtaif B, Levkovitz Y, Nordenberg J, Taler M, Korov I and Weizman A: Phenothiazines induce apoptosis in a B16 mouse melanoma cell line and attenuate in vivo melanoma tumor growth. Oncol Rep 15(1): 107-112, 2006.

28 Choi AR, Kim JH and Yoon S: Thioridazine specifically sensitizes drug-resistant cancer cells through highly increase in apoptosis and P-gp inhibition. Tumour Biol 35(10): 9831-9838, 2014.

29 Ferreira RJ, dos Santos DJ and Ferreira MJ: P-glycoprotein and membrane roles in multidrug resistance. Future Med Chem 7(7): 929-946, 2015.

30 Efferth T, Volm M: Reversal of doxorubicin-resistance in sarcoma 180 tumor cells by inhibition of different resistance mechanisms. Cancer Lett 70(3): 197-202, 1993.

31 Park MS, Dong SM, Kim BR, Seo SH, Kang S, Lee EJ, Lee SH and Rho SB: Thioridazine inhibits angiogenesis and tumor growth by targeting the VEGFR-2/PI3K/mTOR pathway in ovarian cancer xenografts. Oncotarget 5(13): 4929-4934, 2014.

32 Yin T, He S, Shen G, Ye T, Guo F and Wang Y: Dopamine receptor antagonist thioridazine inhibits tumor growth in a murine breast cancer model. Mol Med Rep 12(3): 4103-4108, 2015.

33 McConathy J, Owens MJ: Stereochemistry in Drug Action. Prim Care Companion J Clin Psychiatry 5(2): 70-73, 2003.

34 Csonka Á, Spengler G, Martins A, Ocsovszki I, Christensen JB, Hendricks O, Kristiansen JE, Amaral L and Molnar J: Effect of thioridazine stereoisomers on the drug accumulation of mouse lymphoma and human prostate cancer cell lines in vitro. In Vivo 27(6): 815-820, 2013.

35 Svendsen CN, Froimowitz M, Hrbek C, Campbell A, Kula N, Baldessarini RJ, Cohen BM, Babb S, Teicher MH and Bird ED: Receptor affinity, neurochemistry and behavioral characteristics of the enantiomers of thioridazine: evidence for different stereoselectivities at D1 and D2 receptors in rat brain. Neuropharmacol 27(11): 1117-1124. 1988.
36 Jortani SA, Valentour JC and Poklis A: Thioridazine enantiomers in human tissues. Forensic Sci Int 64(2-3): 165-170, 1994.

37 Ariens EJ: Stereochemistry, a basis for sophisticated nonsense in pharmakinetics and clinical pharmacology. Eur J Clin Pharmacol 26(6): 663-668, 1984.

38 Gruber A, Peterson C and Reizenstein P: D-verapamil and Lverapamil are equally effective in increasing vincristine accumulation in leukemic cells in vitro. Int J Cancer 41(2): 224-226, 1988.

39 Szabó D, Molnár J: The role of stereoselectivity of chemosensitizers in the reversal of multidrug resistance of mouse lymphoma cells. Anticancer Res 18(4C): 3039-3044, 1998.

40 Ramu A, Spanier R, Rahamimoff $\mathrm{H}$ and Fuks Z: Restoration of doxorubicin responsiveness in doxorubicin-resistant P388 murine leukaemia cells. Br J Cancer 50(4): 501-507, 1984.

41 Ganapathi R, Grabowski D, Turinic R and Valenzuela R: Correlation between potency of calmodulin inhibitors and effects on cellular levels and cytotoxic activity of doxorubicin (adriamycin) in resistant P388 mouse leukemia cells. Eur J Cancer Clin Oncol 20(6): 799-806, 1984.

$42 \mathrm{Ke} \mathrm{XY,} \mathrm{Lin} \mathrm{Ng} \mathrm{VW,} \mathrm{Gao} \mathrm{SJ,} \mathrm{Tong} \mathrm{YW,} \mathrm{Hedrick} \mathrm{JL} \mathrm{and} \mathrm{Yang}$ YY: Co-delivery of thioridazine and doxorubicin using polymeric micelles for targeting both cancer cells and cancer stem cells. Biomaterials 35(3): 1096-108, 2014.

43 Amaral L, Spengler G, Martins A, Armada A, Handzlik J, KiecKononowicz $\mathrm{K}$ and Molnar J: Inhibitors of bacterial efflux pumps that also inhibit efflux pumps of cancer cells. Anticancer Res 32(7): 2947-2957, 2012.
Received August 29, 2016

Revised September 12, 2016

Accepted September 13, 2016 